\title{
Approaches for modelling and simulation of metal machining - a critical review
}

\author{
Jürgen Leopold* \\ TBZ-PARIV GmbH, 09126 Chemnitz, Germany
}

Received 11 March 2014 / Accepted 17 June 2014

\begin{abstract}
Manufacturing is as old as the human race. Modelling and Simulation of Machining Operations are mainly based on the development of the Natural Sciences. Within the last 40 years there have been dramatically improvements of both: the scientific foundations of models and simulation techniques on one hand side and a strong industrial application on the other hand. The main focus of this paper is a critical assessment of the relevant single modelling methods for the simulation of machining, as well as providing some roadmaps for further directions towards the closed-loop modelling of machining. Limitations are discussed and challenges for the future are highlighted.
\end{abstract}

Key words: Manufacturing, Machining, Modelling, Numerical Methods

\author{
Nomenclature \\ $u_{x}, v_{y}, w_{z}$ Displacements (respectively velocities) \\ $\dot{\varepsilon} \quad$ Strain rate components \\ $\sigma, \tau \quad$ Stress components \\ $\varepsilon_{\text {eff }} \quad$ Effective strain \\ $k \quad$ Yield shear stress
}

\section{Introduction}

To understand the progress in manufacturing and the associated modelling and simulation methods, a short look back in to the history will identify the next important steps of development and application.

Starting with very simple cutting tools and hand driven technology, the industrial revolution opened the chance to use mechanical energy in addition to man-power with the development and design of machine tools, applied up to the present century. To the classical design, a new concept - Parallel Kinematic Machine Tools (PKM) - has been developed and introduced into industry. Compared with Henry Ford's principle of Mass Production, the main step forward in general manufacturing technology from "Conventional machining" processes was started with the "Flexible Machine Tool System" (FMS) concept. This development, in conventional machine tools, PKM and FMS has been driven by the objectives of increasing

*email: jleopold@tbz-pariv.de product quality whilst retaining higher manufacturing productivity, cost reduction and environment protection. The development and application of relevant models and simulation techniques has a very simple background: Machining is the most predominant manufacturing operation in terms of volume and expenditure. Machined components are used in almost every type of manufactured product. It has been estimated that machining expenditure contributes to approximately $5 \%$ of the GDP in developed countries, while in the US alone it translates into approximately $\$ 250 \mathrm{~B}$ per year [1]. In the face of worldwide competition, the time-to-market of new products can be responsible for economic survival. Advanced modelling and simulation techniques can be a competitive advantage for companies. Returning to the short history of manufacturing (Figure 1), the challenge of further modelling and simulation techniques application are in the increasing of the accuracy for the single model on one hand side but more and more on the application of the so called "Closed-loop-principle" [2] in modelling. This will be pointed out within the next section.

\section{Closed-loop principle of modelling}

The manufacturing of a workpiece can be a very complex situation.

The main goal of machining is the manufacturing of a workpiece with specified properties: geometrical properties (length, diameter, concentricity, etc.); surface properties (roughness, waviness, polish, etc.); sub-surface properties (residual stress; crack-free, etc.), mechanical stability, etc. 

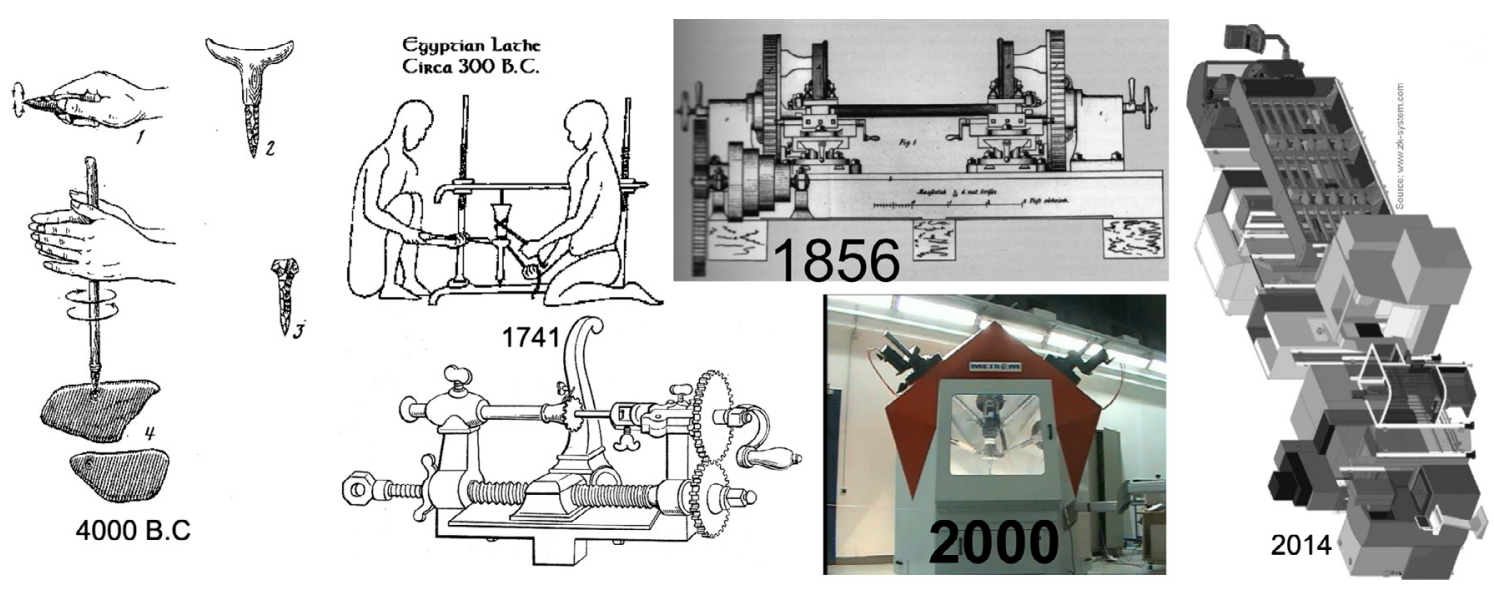

Figure 1. Main steps in manufacturing from past to present.

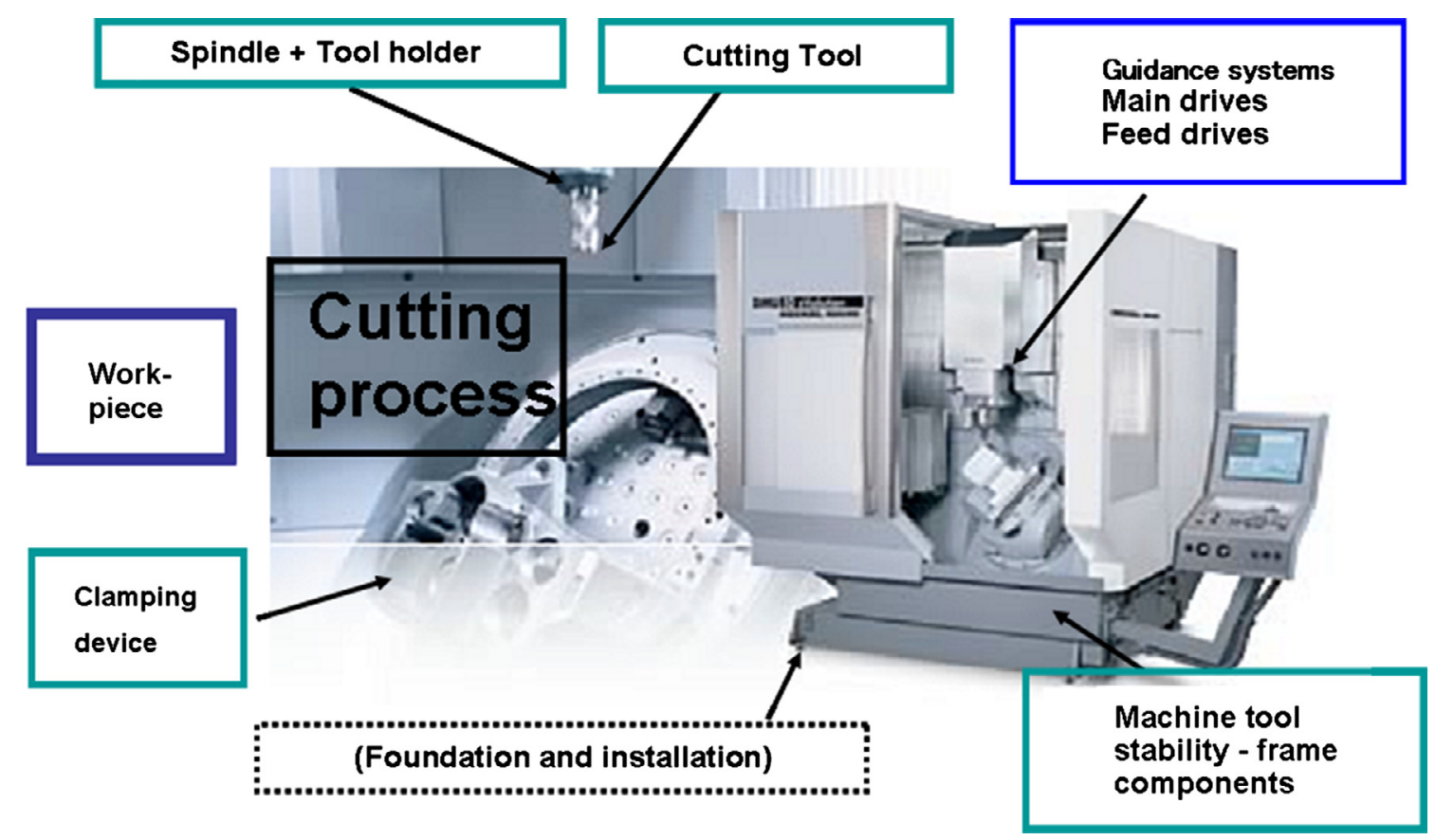

Figure 2. Machining of pre-defined workpieces.

To manufacture a product with such properties, a complex system (Figure 2) must be applied.

Following Georg Schlesinger's postulate, that the "profit will be determined at the cutting tool tip" - the cutting tool is the most important component part of the closed-loop modelling principle. Geometrically properties such as length, flute geometry, tool-tip geometry (rake; chip-former), microgeometry, cutting tool material and coatings; coolant bore holes and design; mechanical stability, clamping areas of the tool within the tool holder, etc. The interaction of the cutting tool with the workpiece is responsible for the generation of the new workpiece, which is why the workpiece is one of the next main modelling part in this system. Typically single modelling systems are focussing on only this interaction - with no deformable cutting tool and also no deformable workpiece. This is commonly used - but did not represent the real situation in manufacturing. The workpiece geometry can be realized in different steps (roughing and finishing) - but in the airplane industry for instance, there are often thin-walled parts manufactured. These parts are commonly produced by casting and can include previously-induced residual stresses. The physical based machining residual stresses must be superposed with the residual stressed caused by previously processes and can deform the final part into an undesirable condition. A similar situation can be found for parts coming from previously forming operations. In addition to this serious problem, the simulation techniques require the workpiece properties and the material law for this workpiece (which depend on strain, strain-rate and temperature for the contemporary homogeneously and isotropic modelling world).

Both the cutting tool and the workpiece are fixed within the machine, which is why on one hand machine tool properties 


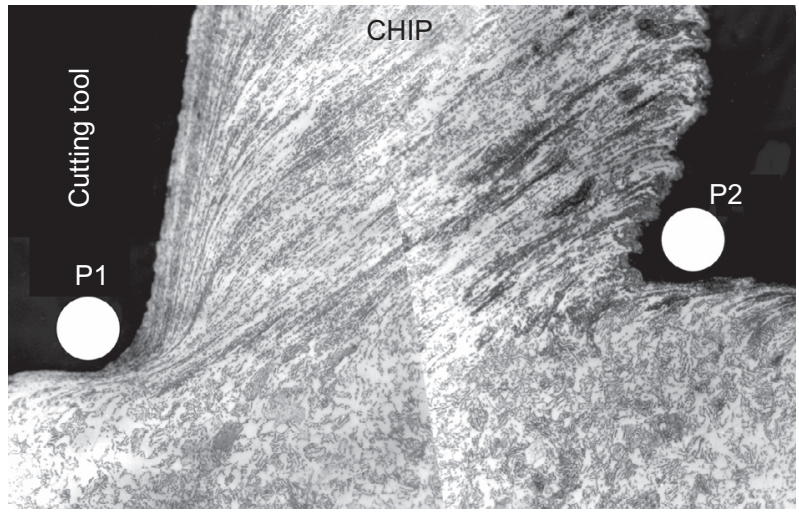

Figure 3. Metallographic view of the chip formation zone.

such as damping and stiffness and also the same properties for the spindle and tool holder within the machine tool, both being influenced by the interaction of the chip-formation process at the cutting tool tip with the workpiece. On the other hand, the clamping device with similar properties (stability; stiffness; damping) also influences considerable the machining process itself. In addition, most of the machining operations are based on cooling and lubrication processes, so this liquid situation must be included with in model.

Following the above very short discussion of the simulation, the final focus for modelling and simulation must be on the development of closed-loop models. The next section will give an overview of contemporary modelling and simulation methods, applied in machining and will be followed by the "white" areas in modelling and simulation.

\section{Modelling and simulation techniques}

\subsection{Slip-line method}

Consider the physically based machining situation of the tool-tip interaction with the workpiece [3]. The surface of the "old" workpiece is on the left-side and that of the new one on the right side of Figure 3.

The originally structure of the previous workpiece surface on the left side is dramatically deformed into the chip area. The line (or area) from tool tip Point P1 to the free surface Point $\mathrm{P} 2$ is called the shear line (or shear plane) and has been defined by the modelling pioneers about 130 years ago (Time - first shear line equation [4]; Merchant 1944 - the so-called Merchant circle [5]) concerned with previous experimental investigation by Tresca [6], Mallok [7] and Svorykin [8].

With the definition of the shear-line, the well known slipline method in chip-formation was born. The principles are summarized briefly below [3].

In addition to the usual assumptions that the metal is isotropic and homogeneous, the common approach involves the following:

- the metal is rigid-perfectly plastic; this implies the neglect of elastic strains and treats the flow stress as a constant,

- deformation is by plane strain,
- possible effects of temperature, strain rate and time are not considered,

- there is a constant shear stress at the interfacial boundary. Usually, either a frictionless condition or sticking friction is assumed.

The principal ways in which slip-line field theory fails to take account of the behaviour of real materials are:

- It deals only with non-strain-hardening materials.

- There is no allowance for creep or strain-rate effects. The rate of deformation at each given point in space and in the deforming body is generally different, and any effect this may have on the yield stress is ignored.

- All inertia forces are neglected and the problems treated as quasi-static (a series of static states).

- In the cutting operations which impose heavy deformations, most of the work done is dissipated as heat; the temperatures attained may affect the material properties of the body or certain physical characteristics in the surroundings, e.g. lubrication.

The following equations are the basics for the slip-line method.

\subsubsection{Plane plastic strain}

Since elastic strains are neglected, the plastic strain increments (or strain-rates) may be written in terms of the displacements (or velocities) $u_{x}(x, y), v_{y}(x, y), w_{z}=0$, as below:

$$
\begin{gathered}
\dot{\varepsilon}_{x}=\frac{\partial u_{x}}{\partial x} \quad \dot{\gamma}_{x y}=\frac{1}{2}\left(\frac{\partial u_{x}}{\partial y}+\frac{\partial v_{y}}{\partial x}\right), \\
\dot{\varepsilon}_{y}=\frac{\partial v_{y}}{\partial y} \quad \dot{\gamma}_{y z}=\frac{1}{2}\left(\frac{\partial v_{y}}{\partial z}+\frac{\partial w_{z}}{\partial y}\right)=0, \\
\dot{\varepsilon}_{z}=\frac{\partial w_{z}}{\partial z}=0 \quad \dot{\gamma}_{z x}=\frac{1}{2}\left(\frac{\partial w_{z}}{\partial x}+\frac{\partial u_{x}}{\partial z}\right)=0 .
\end{gathered}
$$

\subsubsection{State of stress}

It follows from the Levy-Mises relation that $\tau_{x y}$ and $\tau_{y z}$ are zero and therefore that $\sigma_{z}$ is a principal stress. The Levy-Mises relationship between stress and strain for an ideal plastic solid where the elastic strain are negligible is as below:

$$
\sigma=\left(\begin{array}{ccc}
\sigma_{x x} & \tau_{x y} & 0 \\
\tau_{x y} & \sigma_{y y} & 0 \\
0 & 0 & \sigma_{z z}
\end{array}\right)=\left(\begin{array}{ccc}
\sigma_{x x} & \tau_{x y} & 0 \\
\tau_{x y} & \sigma_{y y} & 0 \\
0 & 0 & \frac{1}{2}\left(\sigma_{x x}+\sigma_{y y}\right)
\end{array}\right)
$$

It follows that the plastic strain increment $\partial \varepsilon_{z z}=0$.

The material is incompressible, $\dot{\varepsilon}_{x}^{\prime}=-\hat{\varepsilon}_{y}^{\prime}$, and each incremental distortion is pure shear. The state of stress throughout the deforming material is represented by a constant yield shear stress $k$, and a hydrostatic stress $-p$ which in general varies 


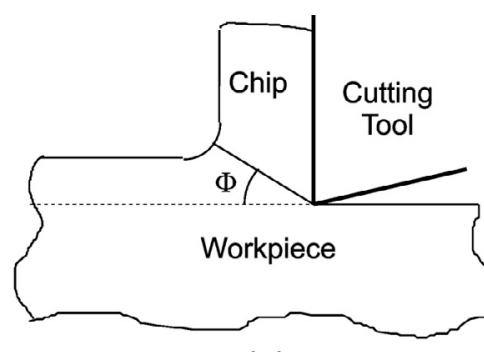

(a)

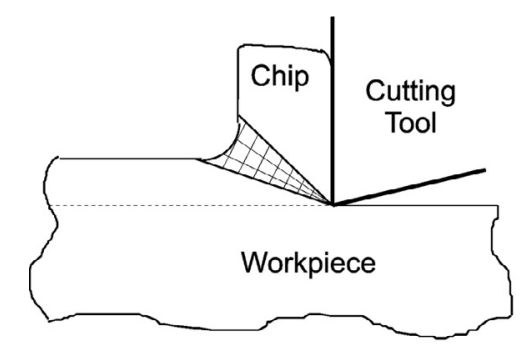

(d)

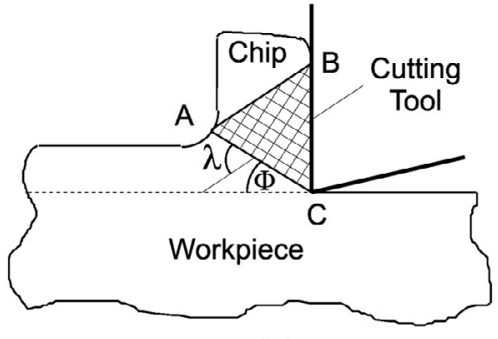

(b)

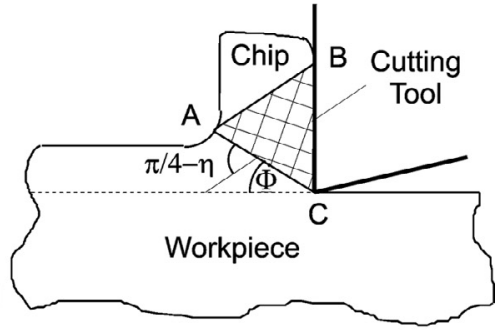

(c)

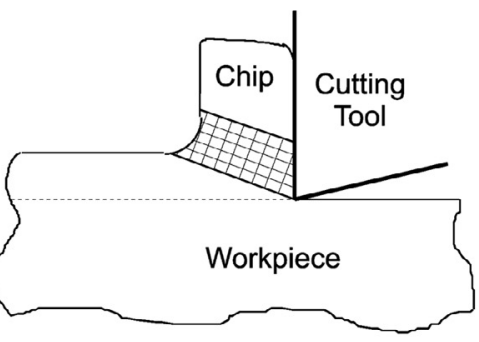

(e)

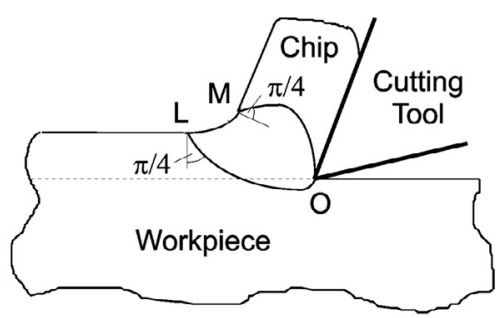

(f)

Figure 4. Selected examples for slip-line field solutions in machining.

from point to point throughout the material. $k$ is the yield shear stress in plane strain and the yield criterion for this condition is:

$$
\tau_{x y}^{2}+\left(\sigma_{x}-\sigma_{y}\right)^{2} / 4=k^{2},
$$

where $k=Y / 2$ for the Tresca criterion and $k=Y / \sqrt{3}$ for the Mises criterion.

The state of stress at any point in the deforming material may be represented in the Mohr circle diagram. Together with Hencky's hydrostatic stress conditions along slip-lines and Geiringer velocity field equation the initial equations can be solved graphically or analytically.

Over the last 70 years this method has been used in basic research by hundreds of scientists (Merchant 1945; Lee and Shaffer 1951; Shaw 1955; Palmer and Oxley 1959; Weber 1969; Stevenson and Oxley 1970; Makino and Usui 1973; Fang and Jawahir 2002). For analytically solution, the computation time compared with numerically methods extreme short. This is responsible for the ongoing investigations, despite the main disadvantages (Figure 4).

\subsection{Finite Element Modelling (FEM)}

With the design and manufacturing of the computer [9] new numerical methods by mathematicians have been developed. Figure 5 gives a short history of FEM application with respect to metal cutting simulation.

There are two main FEM concepts: the EULERIAN flow formulation and LANGRANCE's formulation.

In a very earlier stage of chip formation simulation, the Eulerian FEM principle [10] was applied to steady-state machining $[3,11-15]$.

The plastic metal flow can be considered as an incompressible non-Newtonian flow problem with the following unknown quantities: $v$ - flow velocity and

$p$ - hydrostatic pressure

defined by the differential equations:

$$
\begin{aligned}
\operatorname{div} v=00 & \text { (incompressibility condition) } \\
-\operatorname{div}[\sigma]=\rho g & \text { (equilibrium equation, i.e. balance } \\
& \text { of internal and external forces) }
\end{aligned}
$$

where $[\sigma]$ is the stress tensor and $\rho g$ represents the external forces.

For incompressible materials only the deviatoric stress tensor $\left[\sigma^{\prime}\right]=[\sigma]+p[I]([I]$ is the unity tensor) is influenced by the effective strain $\varepsilon_{\text {eff }}$ and the strain rate tensor $[\dot{\varepsilon}]$ in the form

$$
\begin{gathered}
{\left[\sigma^{\prime}\right]=2 \eta\left(\dot{\varepsilon}_{\text {eff }}, \varepsilon_{\text {eff }}\right)[\dot{\varepsilon}],} \\
\varepsilon_{\text {eff }}=\frac{2}{\sqrt{3}} \sqrt{J_{2}([\varepsilon])}, \dot{\varepsilon}_{\text {eff }}=\frac{2}{\sqrt{3}} \sqrt{J_{2}([\dot{\varepsilon}])}, \\
J_{2}-2 \text { nd tensor invariant. }
\end{gathered}
$$

The uniaxial flow stress $\sigma_{\text {eff }}$ of the workpiece metal is assumed to be governed by the general flow rule

$$
\sigma_{\text {eff }}=\eta\left(\dot{\varepsilon}_{\text {eff }}\right) \dot{\varepsilon}_{\text {eff }},
$$

$$
\text { with } \eta\left(\dot{\varepsilon}_{\text {eff }}\right)=\frac{\sigma_{y}+\left(3 \eta_{0} \dot{\varepsilon}_{\mathrm{eff}}\right)^{1 / m}}{3 \dot{\varepsilon}_{\mathrm{eff}}}
$$

and the material parameter are according to the temperature $\theta$

$$
\begin{gathered}
\sigma_{y}(\theta)=\sigma_{y}^{(1)}+\sigma_{y}^{(2)} \cdot \exp \left(\sigma_{y}^{(3)} \cdot \theta\right), \\
\eta_{0}(\theta)=\eta_{0}^{(1)}+\eta_{0}^{(2)} \cdot \exp \left(\eta_{0}^{(3)} \cdot \theta\right), \\
m(\theta)=m^{(1)}+m^{(2)} \cdot \theta .
\end{gathered}
$$


350 Mio years B.C.

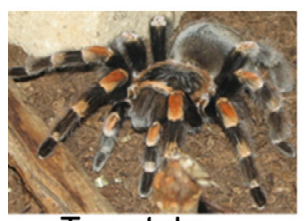

Tarantula

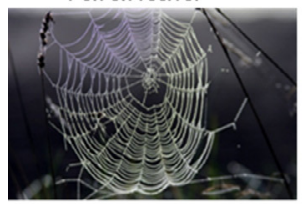

First "adaptive

FE grid"?
H. Gründemann

U. Semmler

K. Hoyer

J. Leopold

H. WEBER

KARL-MARX

-STADT now:

CHEMNITZ

First FE-code

applied for

steady-state

cutting

"FEPAS"

1976

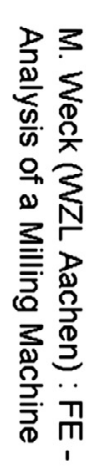

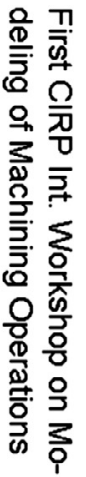

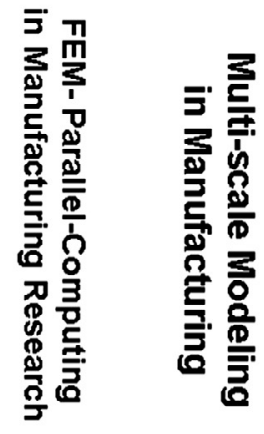

1978
1998

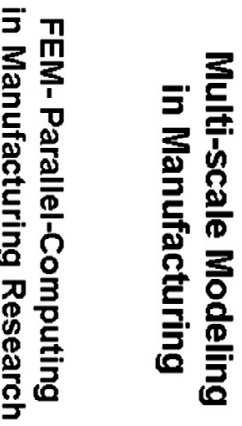

2011

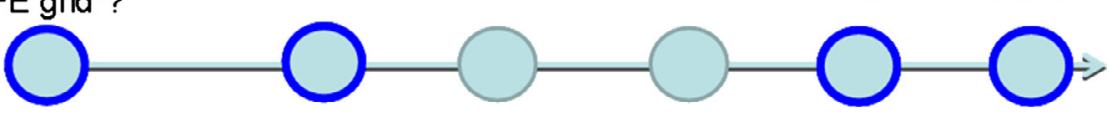

Figure 5. Finite element application in the modelling and simulation of metal cutting.

This general law includes linear Newtonian and the nonlinear Bingham and Norton-Hoff laws as special cases. The parameters in the flow rule may depend on the strains. Instead of the flow rule of type, other formulations for the thermo-viscoplastic behaviour of the material may be used. In general, the flow rules give a functional relation of the dependence of the flow stress on the actual effective strain rate, the actual effective strain and the actual temperature. Typical material laws are the JohnsonCook [16] and the Zerilli-Armstrong [17] law.

Frictional stress $\tau_{F}$ on the tool rake face may be defined using a modified model of Usui and Hoshi [18]:

$$
\tau_{F}=k \cdot \sigma_{\mathrm{eff}}\left(1-e^{-\mu_{F} \frac{\sigma_{n}}{\sigma_{\mathrm{eff}}}}\right),
$$

where $k$ is the friction factor $(\leq 1.0)$ and $\mu_{F}$ is the friction number.

Heat flux within the workpiece is modelled by the stationary heat conduction-convection equation

$$
\rho c_{p} v \nabla \theta=\nabla(\lambda \nabla \theta)+\dot{w}
$$

where $\rho c_{p}$ represents the heat capacity, $\lambda$ is the thermal conductivity and $\dot{w}$ is the heat dissipation rate. The parameters $\lambda$ and $c_{p}$ depend on the temperature. It may be assumed that the heat dissipated is equal to the plastic work rate $\dot{w}=\sigma_{\text {eff }} \cdot \dot{\varepsilon}_{\text {eff }}$.

In comparison to the steady-state solution with the Eulerian approach, Lagrange's solution can be used for a non-stationary chip-formation application. This approach must be used for the most typical industrial applications such as: tool-workpiece entry or exit; burr-formation simulation; any chip thickness modifications during the machining operation, etc. This approach is more general - but is also much more time consuming in computation. The leading industrial software code [21], is an explicit dynamic, thermo-mechanically coupled finite element modeling package specialized for metal cutting. The principle is pointed out in the following equations [21].

The balance of linear momentum is written as:

$$
\sigma_{i j, j}+\rho b_{i}=\rho \ddot{u}_{i} .
$$

\subsubsection{Thermal equations}

Heat generation and transfer are handled via the second law of thermodynamics. A discretized weak form of the first law is given by

$$
C \dot{T}_{n+1}+K T_{n+1}=Q_{n+1},
$$

where $T$ is the array of nodal temperatures,

$$
C_{a b}=\int_{B t} c \rho N_{a} N_{b} \mathrm{~d} V_{o}
$$

is the heat capacity matrix

$$
K_{a b}=\int_{B 0} D_{i j} N_{a, i} N_{b, j} \mathrm{~d} V
$$

is the conductivity matrix

$$
Q_{a}=\int_{B t} s N_{a} \mathrm{~d} V+\int_{B \tau q} h N_{a} \mathrm{~d} S
$$

is the heat source array, with $h$ having the appropriate value for the chip or tool. In machining applications, the main sources of heat are plastic deformation in the bulk and frictional sliding at the tool-workpiece interface.

\subsubsection{Constitutive model and material characterization}

In order to model chip formation, constitutive modeling for metal cutting requires determination of material properties at high strain rates, large strains and short heating times and is quintessential for the prediction of segmented chips due to shear-localization. The increase in flow stress due to strain rate sensitivity is accounted for with the relation

$$
\left(1+\frac{\dot{\varepsilon}^{p}}{\dot{\varepsilon}_{0}^{p}}\right)=\left(\frac{\bar{\sigma}}{g\left(\varepsilon^{p}\right)}\right)^{m_{1}}
$$

where $\bar{\sigma}$ is the effective Mises stress, $g$ the flow stress, $\varepsilon^{p}$ the accumulated plastic strain, $\dot{\varepsilon}_{0}^{p}$ a reference plastic strain rate, and $m_{1}$ is the strain rate sensitivity exponent. A power 

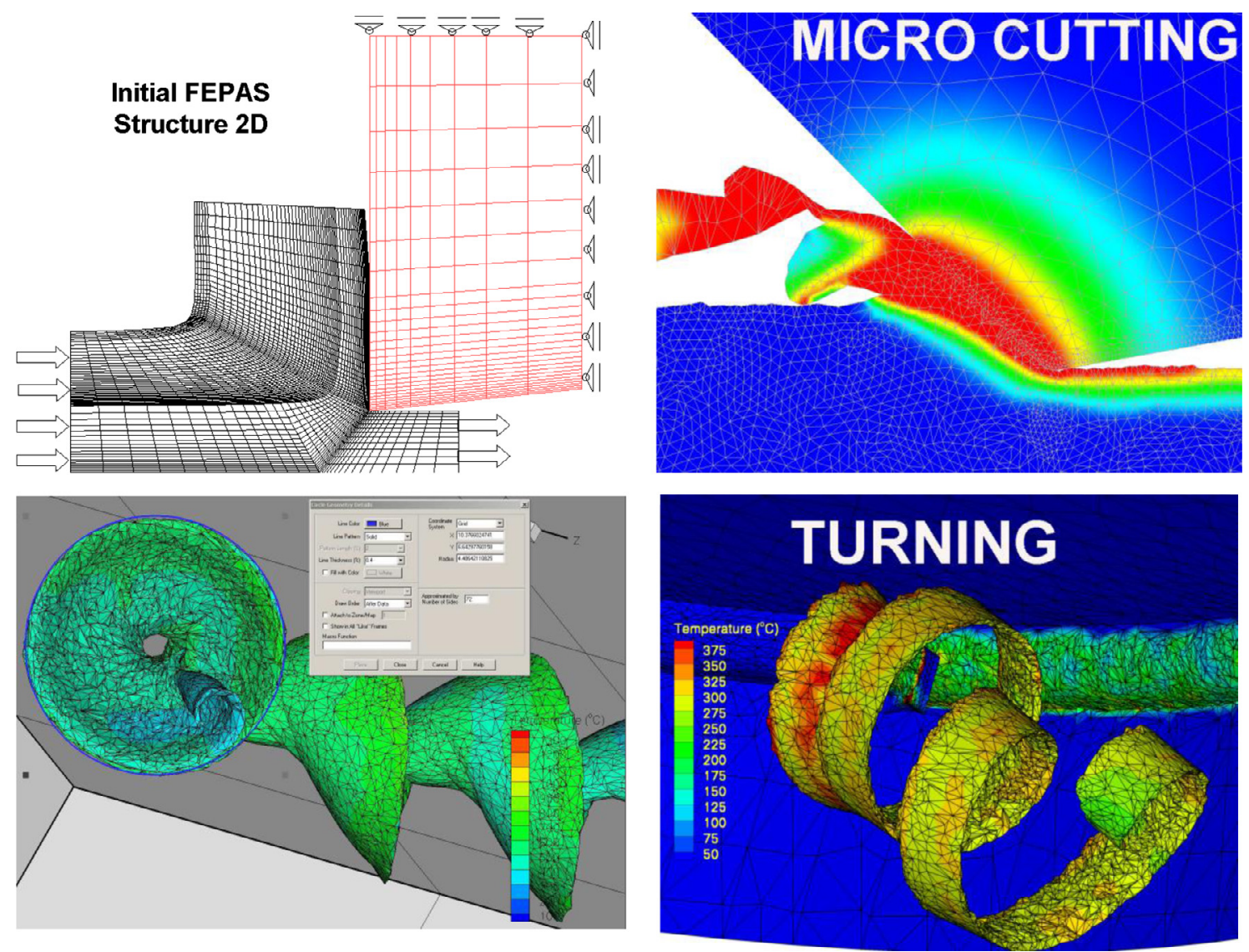

Figure 6. From EULER 2D up to LAGRANGE 2D/3D simulation - examples.

hardening law model is adopted with thermal softening which gives

$$
g=\sigma_{0} \Theta(T)\left(1+\frac{\varepsilon^{p}}{\varepsilon_{0}^{p}}\right)^{1 / n}
$$

where $n$ is the hardening exponent, $T$ the current temperature, $\sigma_{0}$ is the initial yield stress at the reference temperature $T_{0}, \varepsilon_{0}^{p}$ the reference plastic strain, and $\Theta(T)$ is a thermal softening factor ranging from 1 at room temperature to 0 at melt and having the appropriate variation in between.

Next Figure 6 indicates the grand step forward in industrially driven machining simulations and application.

In addition to this "single" numerical philosophy (EULERIAN or LAGRANGE), the Arbitrary Lagrangian - Eulerian (ALE) technique combines the unique features of Lagrangian and Eulerian formulations, and adopts an explicit solution technique for fast convergence [19]. While the ALE technique with Eulerian boundaries requires a predefined chip geometry assumption, chip formation is free of any geometrical assumption in ALE with Lagrangian boundary conditions [20].

Considering industrial demands, typical 3D-computation times for a drilling operation of more than three month (in the year 2000) have been changed to a few hours by a new numerical algorithm and, above all, due to parallel computing.

Recently [21] the parallel computing capability in chipformation simulation has been extended to up to 38 processors. In the case of time consuming drilling simulation, the total elapsed time can be reduced from about $119 \mathrm{~h}$ to about $7 \mathrm{~h}$. Thus, batch jobs can run overnight with the results being available on the next morning (Figure 7).

For coating-substrate simulations, this method has been developed and applied by [22-27] in the last century. The most time and memory consuming part of the numerical program is the solver for the linear FEM equation systems. Iterative methods should be preferred, because direct solvers have bad error propagation and, due to the unavoidable fill-in, require too much storage when applied to large equation systems. Moreover, the FEM matrices' large condition number, mainly caused by the inevitable high mesh graduation, requires special preconditioning techniques, which is why the Pre-Conditioned Conjugate Gradient Method (PCCG) has been applied for the FEM solver. Additional coarse-mesh pre-conditioning has substantially reduced the necessary number of iterations. The accuracy of FEM simulations on standard hardware is basically limited by the available storage and the acceptable computing time. The application of parallelised software on a distributed memory computer with $N$ processors reduces the computing time to less than the $N$ th part and increases the available storage by almost $N$ times. The software developed for the simulation of coating-substrate-systems on cutting tools is scalable to any number of processors and portable to a variety of hardware and operating systems. The dominating programming model for parallel FEM applications is the Domain Decomposition Method (DDC; Figure 8 ). For $N$ processors, the simulation 


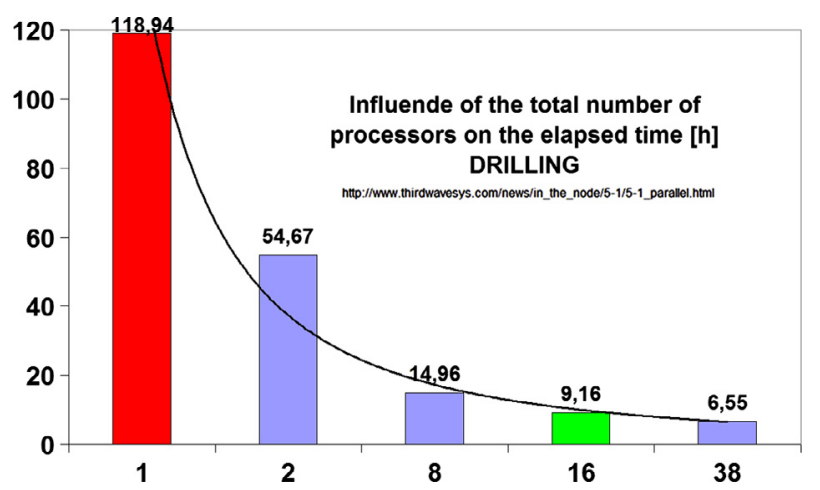

Figure 7. Example for the elapsed time reduction in parallel computing.

domain e.g. the tool's geometrical model, is divided into $N$ disjunctive sub domains and each processor does all the computational work related to "it's" sub domain, with some internal communication for data exchange and control purposes. Based on this parallel FEM software, deformations, strains and stresses caused in coated tools by external loads can be computed on a microscopic scale and become available inside and between the coating layers. Based on computation results with this parallel FEM software, a cutting insert test (workpiece material: GGG-60) with an adopted new coating-substrate system [28] increased the lifetime of the tool by up to $146 \%$.

\subsection{Complementary methods}

Supplementary methods that are used successfully in other scientific applications have been transferred to machining simulations. Figure 9 point out the commonly used complementary methods.

Boundary Element Method (BEM), Finite Variation Method (FVM) and Finite Difference Method (FDM) are used for linear elastically and heat conductivity problems.

The boundary element method is a numerical technique to solve partial differential equations (PDEs) of a variety of physical problems with well defined boundary conditions. The PDE over a problem domain is transformed into a surface integral equation over the surfaces that enclosed the domain. This integral equation can be solved by discretization of the surfaces into small patches - the boundary elements.

The transformation into a surface integral is not possible generally. There is not known a global way to transform the complex thermo-mechanical equations describing the chip and burr formation process to a surface integral equation. Therefore the BEM has been used only for sub problems in machining simulation e.g. for the thermal problem in steady state chip formation [29].

New mathematical methods for the coupling of finite elements and boundary elements for problems in elastoplasticity and for contact problems with friction which yield variational inequalities were developed and applied at the Institute of Applied Mathematics in Hannover [30].
A few years ago [31], a previously developed numerically code based on the Finite Point Set Method (FPM) (or sometimes called the Grid Free Method or Smoothed Particle Hydrodynamics - SPM) [32], has been applied for a simple 2D chip formation simulation (Figure 10). The main advantage could be to delete the second numerically step in Figure 10 - normally used in FEM. For a "relatively good accuracy" [33] the CPU time can be reduced up to approximately 2.75 times less cost compared to the Eulerian model. The basic equations follow the Hydrodynamic's:

$$
\begin{gathered}
\frac{\mathrm{d}}{\mathrm{dt}} \rho=0 \quad \Rightarrow \quad \nabla_{\boldsymbol{V}}=0, \\
\frac{\mathrm{d}}{\mathrm{dt}} v=-\frac{1}{\rho} \nabla p+\frac{\eta}{\rho} \cdot \Delta v+g, \\
\frac{\mathrm{d}}{\mathrm{dt}} T=-\frac{1}{\rho \cdot c} \cdot \nabla(k \cdot \nabla T) .
\end{gathered}
$$

Due to missing friction conditions between chip and cutting tool and a very simple material law, the development was stopped [31]. A recently published new paper [34] did not present any substantial progress in this direction. The authors focused the further development in: "The FPM for the simulation of chip formation still requires considerable development effort however. Thus the algorithms for the calculation of the material behaviour and for the consideration of various boundary conditions such as friction, inertia and heat transfer will be developed further" [34]. In addition, other interesting papers have been published recently $[35,36]$.

Molecular Dynamics simulation applications for cutting has been developed in the earlier 90th of the last century [37-39] and are commonly used for special material removal, such as mono crystalline silicon [40].

\section{Modelling and simulation in the industry - selected examples}

\subsection{Cutting tool optimisation}

State-of-the art in the leading cutting tool companies is the daily job for tool design and tool optimization [41-44]. Investigations are already focused on: the tool tip geometry, the coolant bore design, cutting tool stability, to the chip-geometry design, mainly for deep-hole drilling, the influence of cutting tool material in relation to the workpiece material, etc.

\subsection{High-speed cutting or high-performance cutting}

The influence of high speed or high loads on the stability of the cutting process and the quality of the new surface is widely investigated. There are interesting solutions available due to the holding of special International Conferences [45-47].

\subsection{Dry machining}

From the modelling and simulation point of view is the manufacturing without coolants or lubricants a very welcome 

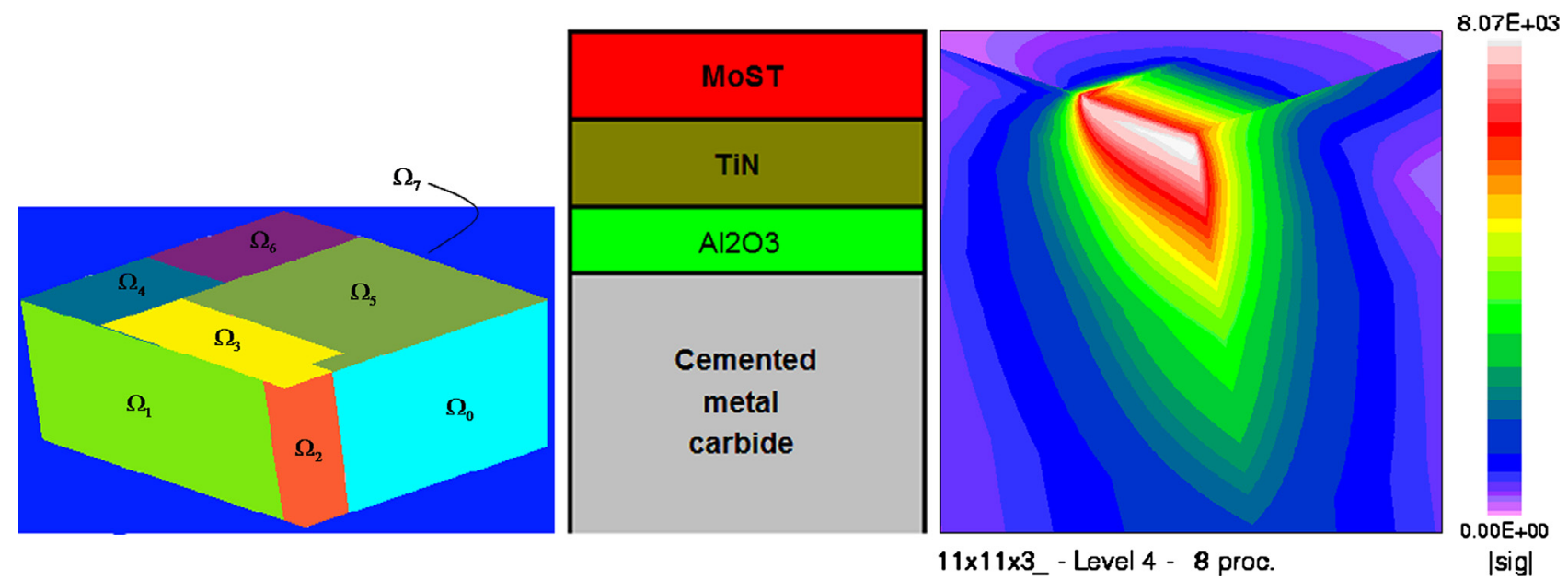

Figure 8. DDC Method applied to coating-substrate optimisation.

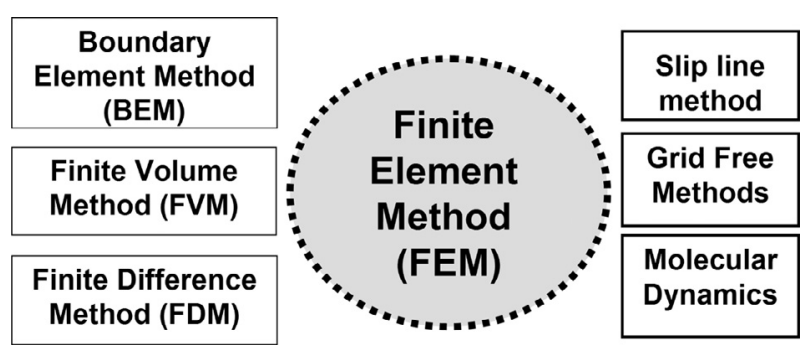

Figure 9. Methods for machining simulations.

task. The boundary conditions of the cutting model are simpler, because no special friction conditions between the chip and cutting tool (rake face, etc.) must be included in to the calculation. Due to the fact, that a lot of cutting operations are not stable enough in dry conditions, leading software tools has included cooling options for coolants and lubricants.

\subsection{Burr-formation and clean manufacturing}

The best choice is: If you do not make the burr, you do not have to remove it. In most cases this philosophy is not applicable in the industrial environment. With modelling and simulation, the generation of burrs can be investigated and good cutting conditions (including cutting tool, coatings, speed, feed, tool geometry, etc.) can be find out to prevent burrs.

In the earlier 90th a quantitative model of burr formation for ductile materials which does not include fracture during orthogonal machining has been proposed [48]. The burr formation mechanism is divided into three parts - initiation, development and formation of the burr with appropriate assumptions. A good overview to the state-of-the art was published recently [49]. Based on the new mechanical principle of the "hydrostatic bowl" [50], the mechanism of burr formation can be better understood.

The hydrostatic bowl as a highly negative hydro-static pressure region immediately below the cutting edge in the workpiece (Figure 11), which acts as a slipstream, may have a positive effect on burr formation as well as on the burr shear zone, assuming that chip and burr will tear off there. A bigger hydrostatic bowl leads to a better burr. The downscaling influences the size and shape of the hydrostatic bowl [51]. The size of the pressure region increases in the course of the time up to the moment when the tool crosses the left edge of the workpiece. The hydrostatic bowl bigger the smaller is the rake angle. Hence there is an obvious influence of the rake angle on the size and depth of the pressure region [52]. In addition, there are additional investigations, concerning the failure criteria [53] to simulate burr-formation, Ultrasonic assisted cutting [54], Modification of the local material properties to prevent burrs [55]. Burr formation and clean ability are closely connected. In addition to prevent burrs in manufacturing, some new methods to increase the clean less within the machine tool has been developed [56]. With standard coatings (modified DLC) as well as new coatings based on nanoscale metallic fluoride powders, the amount of stuck-on chips at the sheet metal surface in a machine tool after the machining of steel and aluminium alloy was reduced by up to $45 \%$ and in dry machining with Nanocer Coatings by up to $94 \%$. Geometrical cutting tool design influences burr formation [57-59].

\subsection{Cryogenic machining}

The most emerging needs of the modern metal cutting operation are to increase the material removal rate with better surface finish, high machining accuracy and acceptable tool life. These objectives can be achieved by reducing the cutting temperature in the cutting zone. In metal cutting, high cutting temperatures are generally reduced by proper selection of process parameters, proper selection and application of coolants and lubricants and using heat- and wear-resistant cutting tool materials - including special coatings. Conventional coolants fail to provide desirable control of cutting temperature in the cutting zone and also they create some techno-environmental problems such as disposal and dermatological problems to the user. These problems were eradicated using liquid nitrogen as a coolant in 

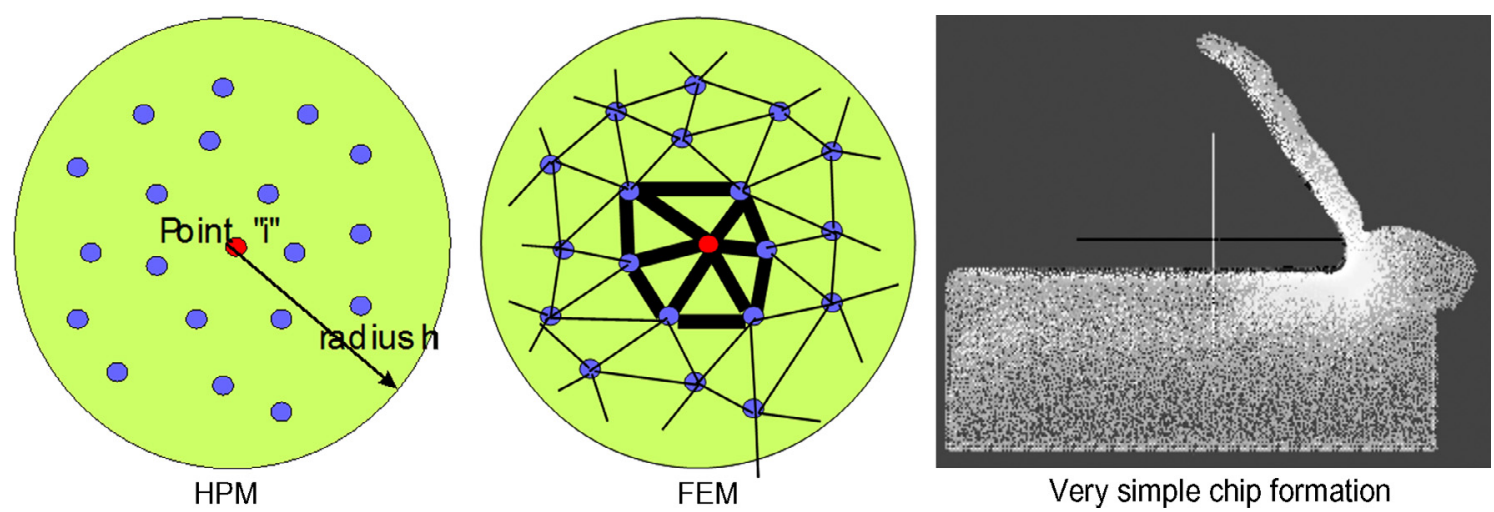

Very simple chip formation

Figure 10. Principles of FPM and a simple example for cutting.

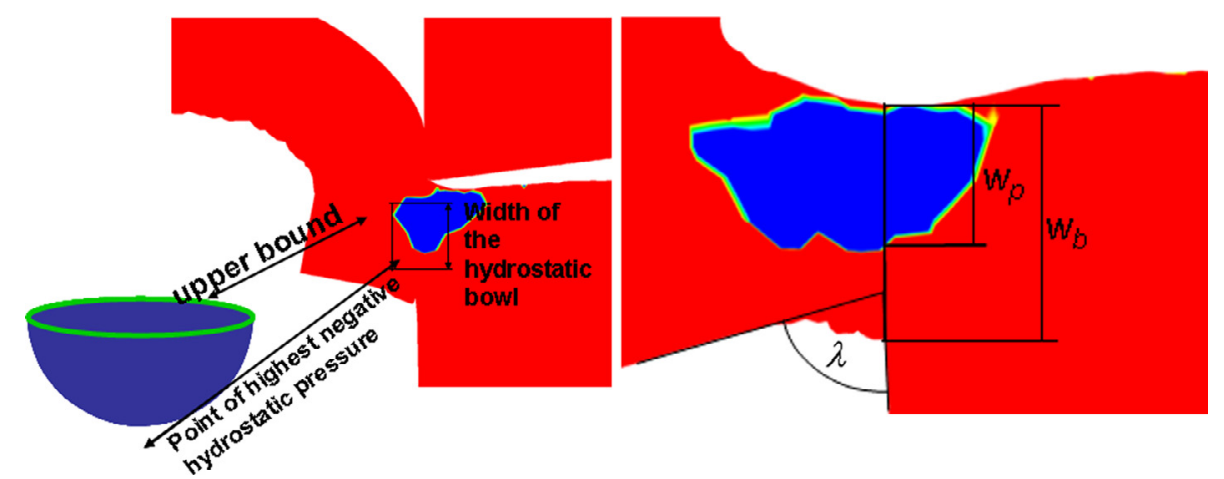

Figure 11. Definition of the "hydrostatic bowl" - applied to burr formation.
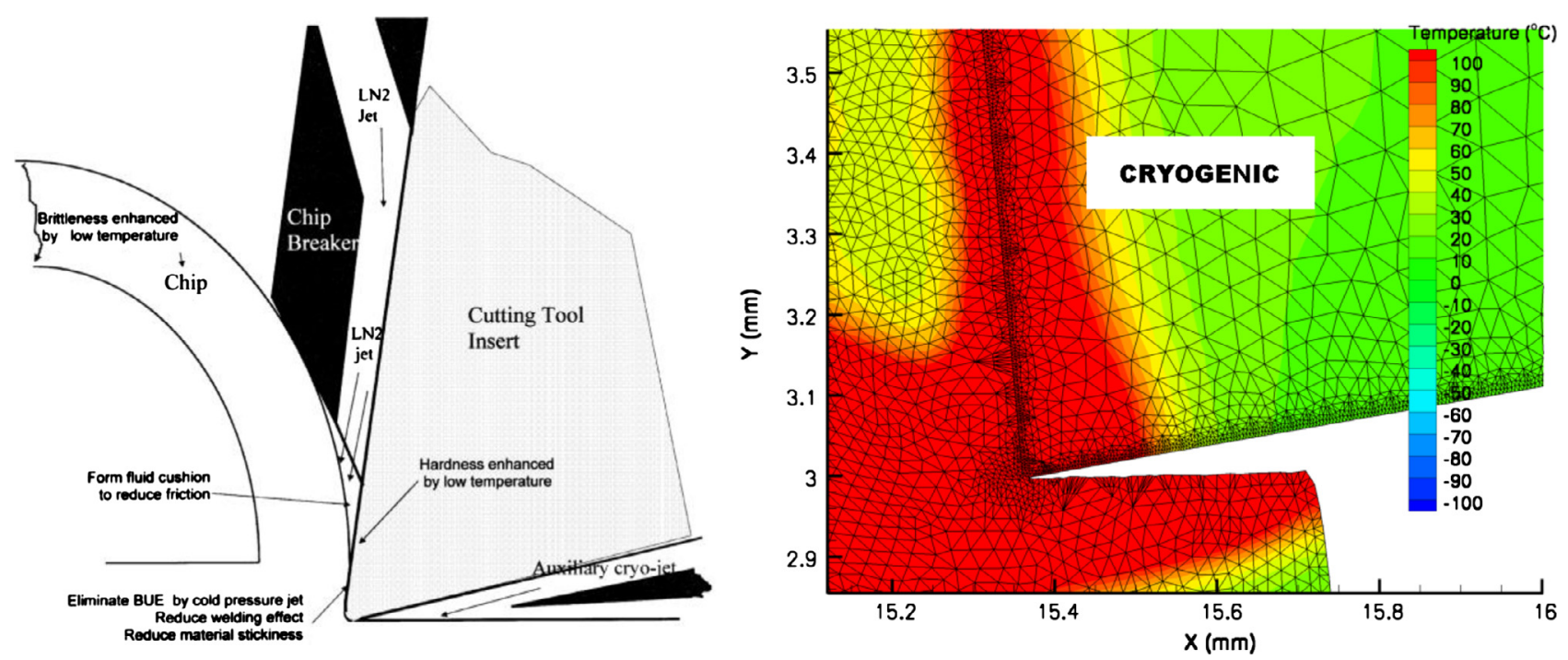

Figure 12. Left the model [60] and right the temperature distribution around the cutting edge with cryogenic cooling.

cryogenic machining due its excellent cooling ability along with environmental friendliness [60-66]. Cryogenic titanium machining can increase cutting-tool life by up to a factor of 10 and double the material-removal rate, compared to conventional machining methods in certain applications [67]. Modelling and Simulation of the chip formation process helps to identify the best available parameters and help to reduce the number of shop floor tests (Figure 12). 

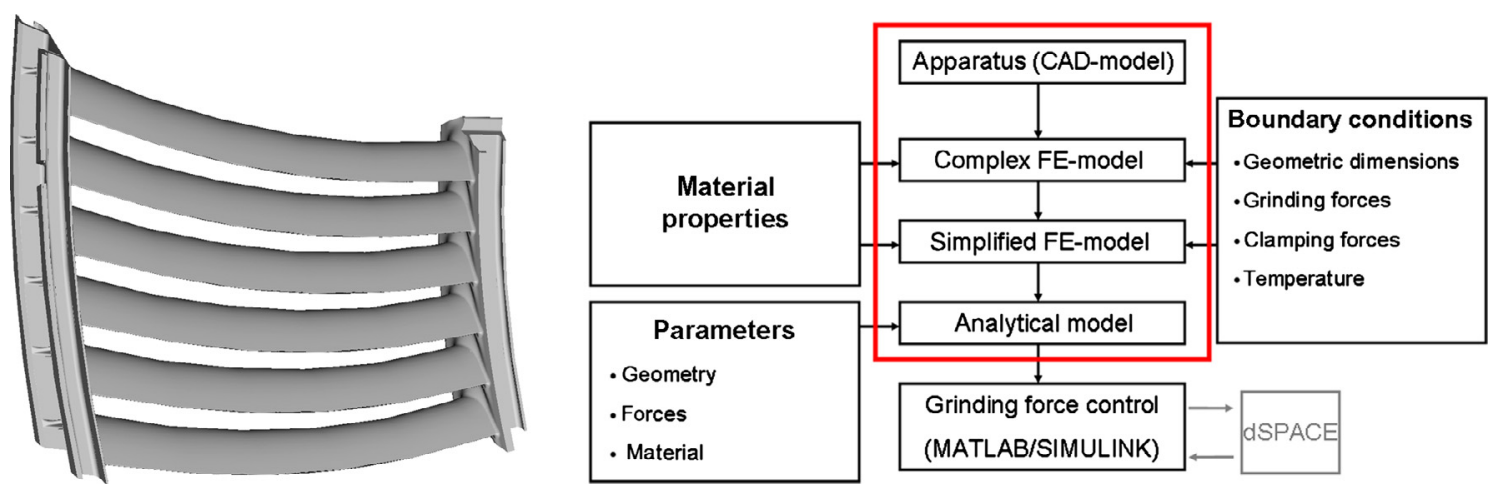

Figure 13. Application of closed-loop-simulation on a nozzle-guide-vane part.

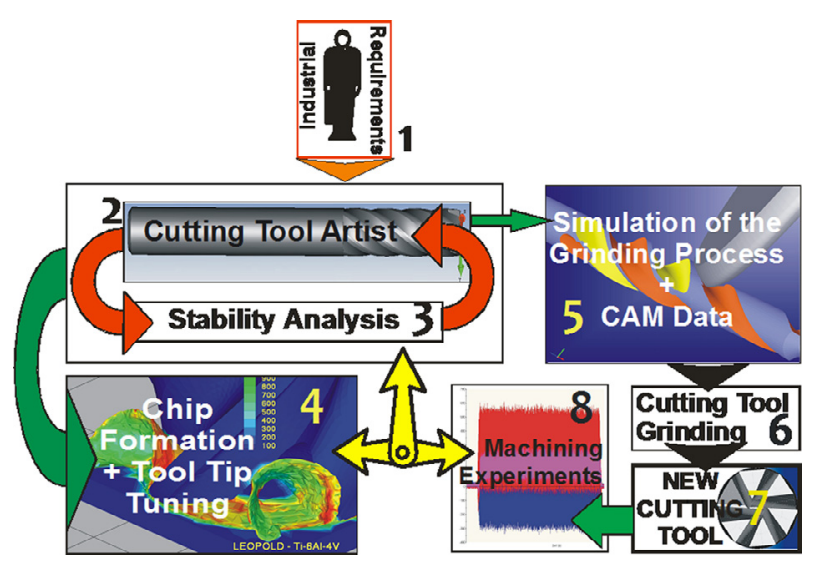

Figure 14. Closed-loop design of cutting tools.

\section{Open issues}

\subsection{Hybrid modelling and closed-loop-design}

Hybrid Modelling is the combination (or extension) for any combination of analytical, numerical, experimental or communication engineering methods.

Well known approach is the combination of the slip-line approach with FEM simulations [68], the hybrid method FEM simulation with the visoplasticity [69-73] and previously discussed modelling techniques together with AI-based methods [74].

This philosophy has been introduced as "house of models" [2]. The most important deficit of knowledge is already in the system approach of modelling and simulation. As discussed in the previous sections, there is an exceptionally great step-forward in physically based modelling and simulation for single solutions. The next step forward is expected to be for a closed-loop-design. There are a few examples, as follow.

\subsubsection{Clamping devices and machining}

The reduction of overall-costs, lead-times and improvement of product quality is one of the main goals in manufacturing today. At the same time innovative materials, including titanium alloys, composites and metal-composite sandwiches, are being used for assembling lighter and increasingly more complex parts. In manufacturing processes, fixturing is used for accurate location and tight holding of the workpiece. The ability to establish and secure desired positions is significant in assessing the effectiveness of a fixture system. Further, product differentiation increases the need of highly efficient, flexible, accurate and automatic fixing systems in industry. Especially in the aerospace and automotive sector the number of low volume, high value and difficult-to-handle products is increasing. Specialised fixtures are economic only within mass production and cannot be reconfigured easily, otherwise the design and construction of modular fixtures are very time consuming and expensive, with problems in repeatability and positioning accuracy. Furthermore, quality and precision cannot be controlled and influenced actively during the manufacturing process and during loading/ unloading. Thus there is a need of active, efficient, flexible and precise fixturing systems, which are fields of research in many sectors of industry nowadays. As a basis of all development processes, the forces acting upon the fixing components during the manufacturing process have to be analysed. An iterative improvement of fixture prototype designs is still common and causes high development costs.

Consequently, an effective modelling and simulation method for the prediction of the workpiece-fixture behaviour during machining is required, which would also enable the possibility of fixture optimisation. Therefore, the finite element method (FEM) is an adequate tool to be used for the simulations.

In [75-77] a complex FEM-model with a huge number of elements has been created followed by a parametric model with similar mechanical properties but fewer elements. The usability of this closed-loop method has been revealed by forecasting the transverse reaction forces acting on knee levers fixing a Nozzle-Guide-Vane (NGV) during shape grinding. With continuum-mechanical principles and a parametric FEM model the calculation time has be reduced dramatically (Figure 13).

\subsubsection{Closed-loop cutting tool design}

The current engineering of tools often proceeds as follows: a model of the tool is developed and a prototype is ground and analyzed. Results are then evaluated by development engineers together with costumers who make appropriate changes to the tool geometry. A new prototype is developed, and the cycle is repeated. Each single iteration demands high costs in terms 

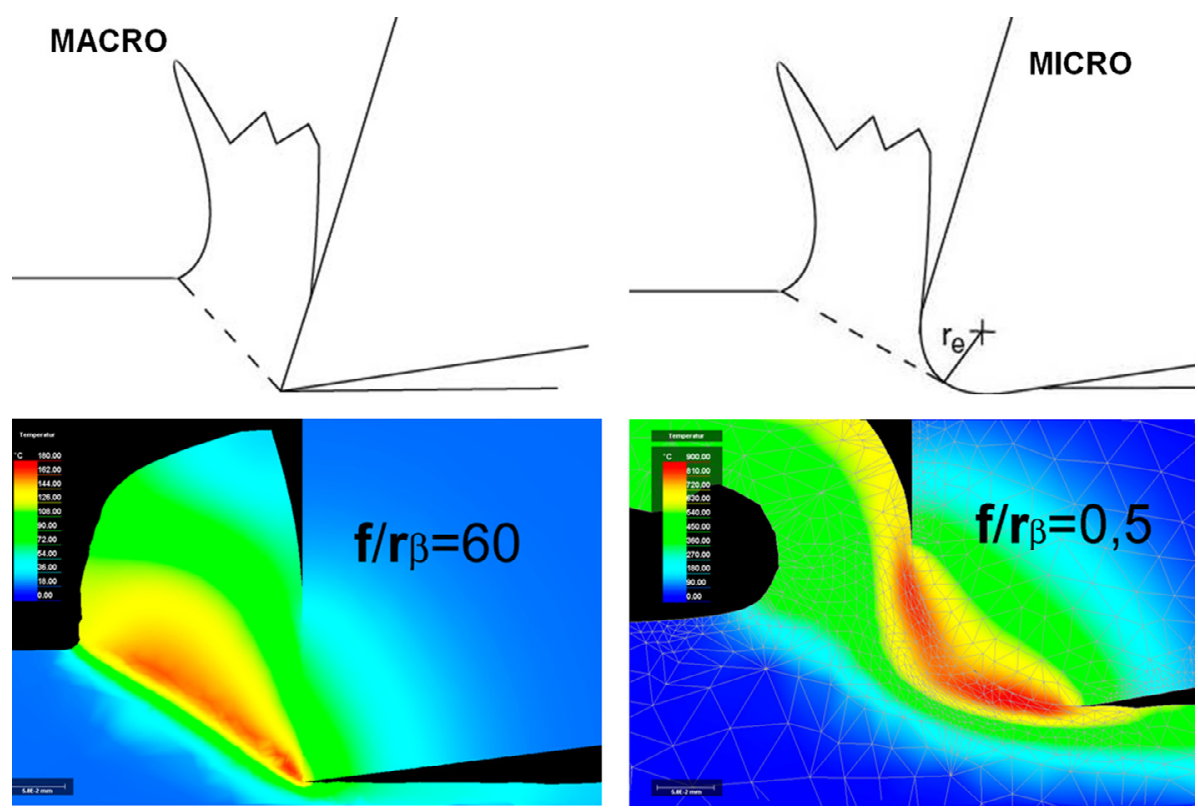

Figure 15. Geometrical differences.
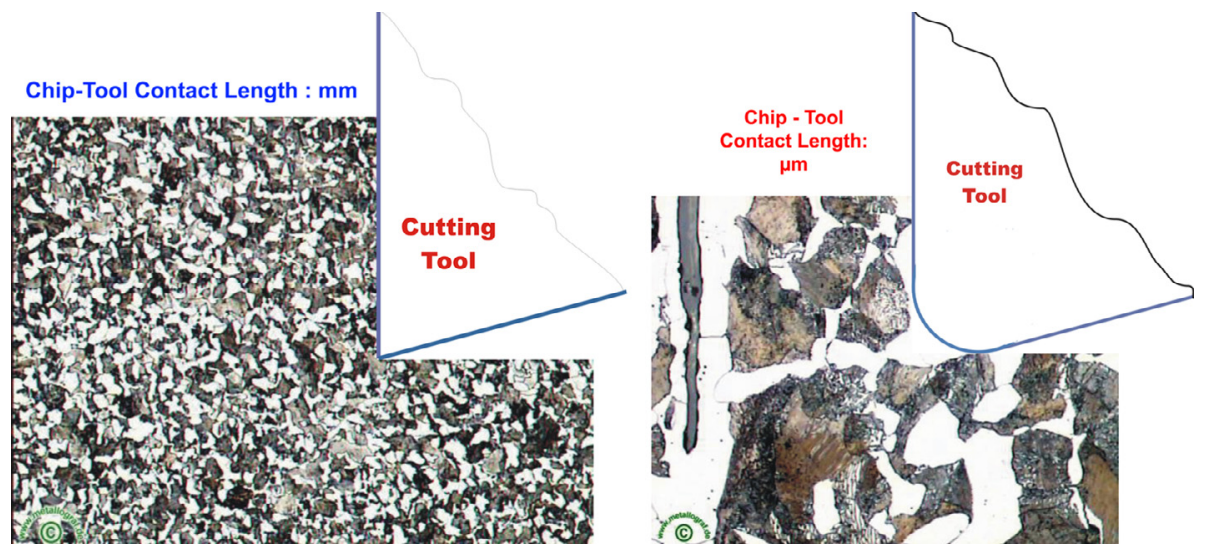

Figure 16. Material differences.

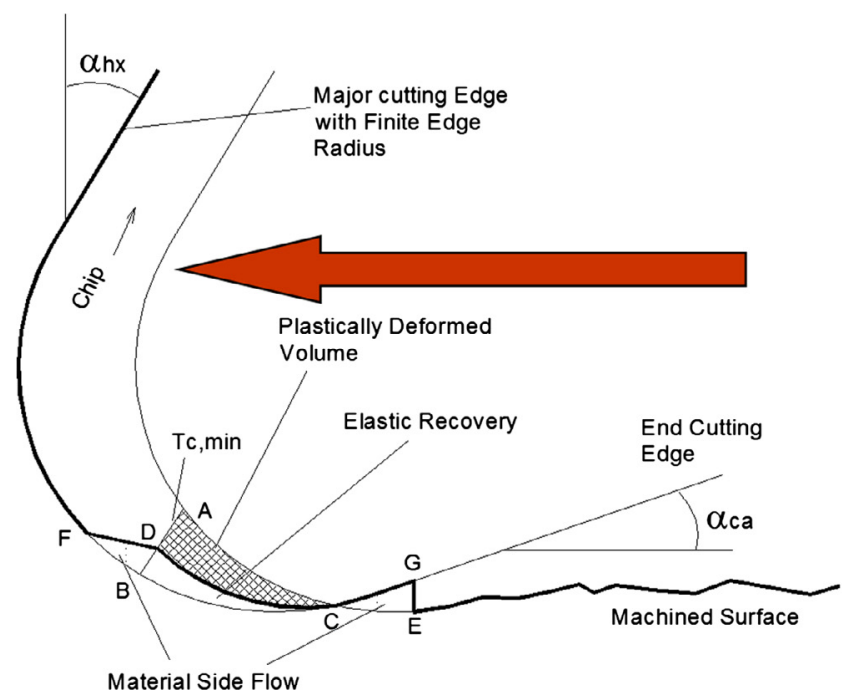

\begin{tabular}{|l|c|}
\hline Rake face & Roughness $\mathrm{R}_{\mathrm{z}}[\mu \mathrm{m}]$ \\
\hline Polished surface & 0,05 \\
\hline Delivery quality & $3,09 \ldots 3,89$ \\
\hline TiAlN - coating & $4,23 \ldots 4,80$ \\
\hline TiN - coating & $4,42 \ldots 5,47$ \\
\hline Grinded surface & $3,30 \ldots 3,91$ \\
\hline
\end{tabular}

Figure 17. Differences in frictional influences near the cutting edge. 


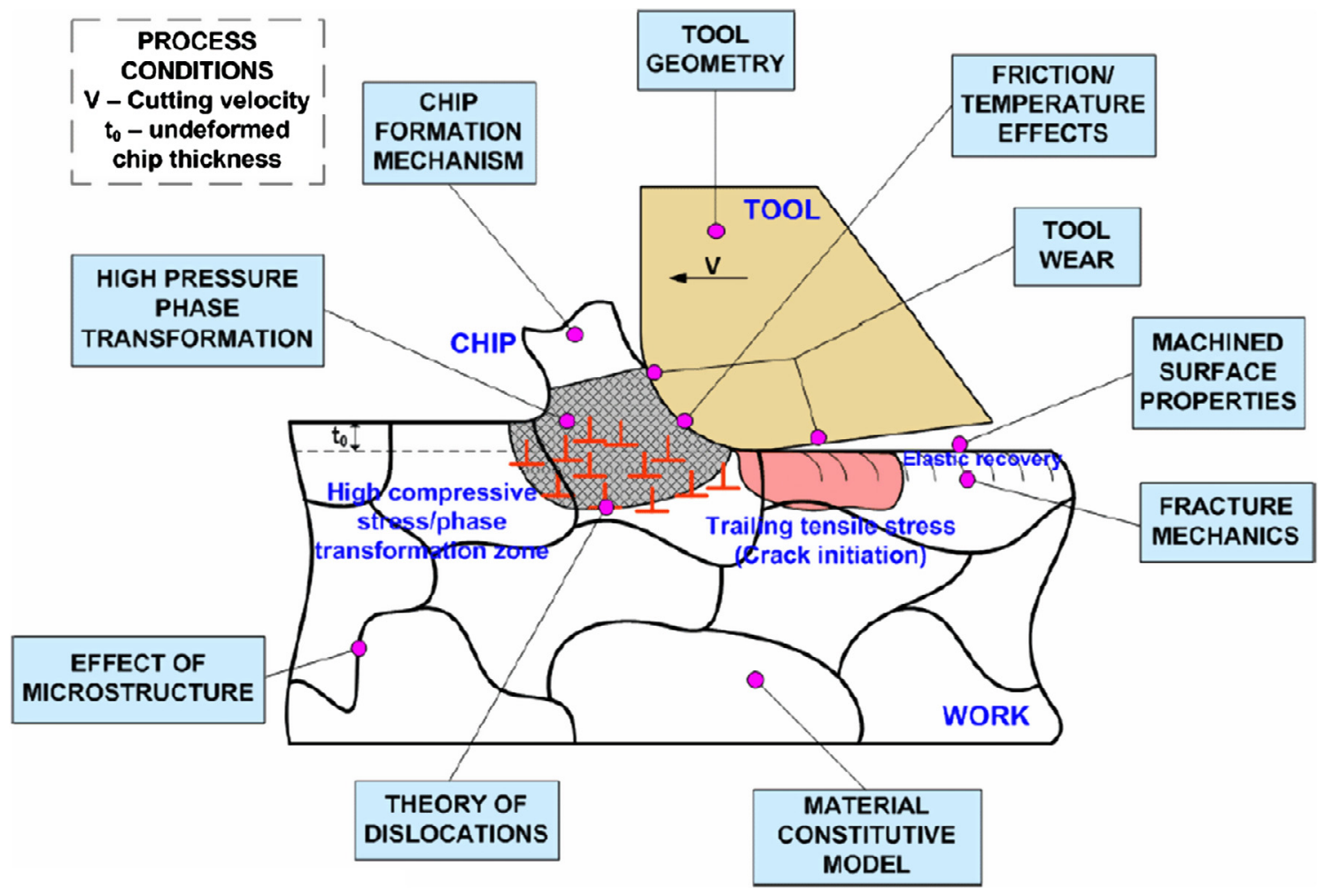

Figure 18. Overall modelling task in micro cutting.

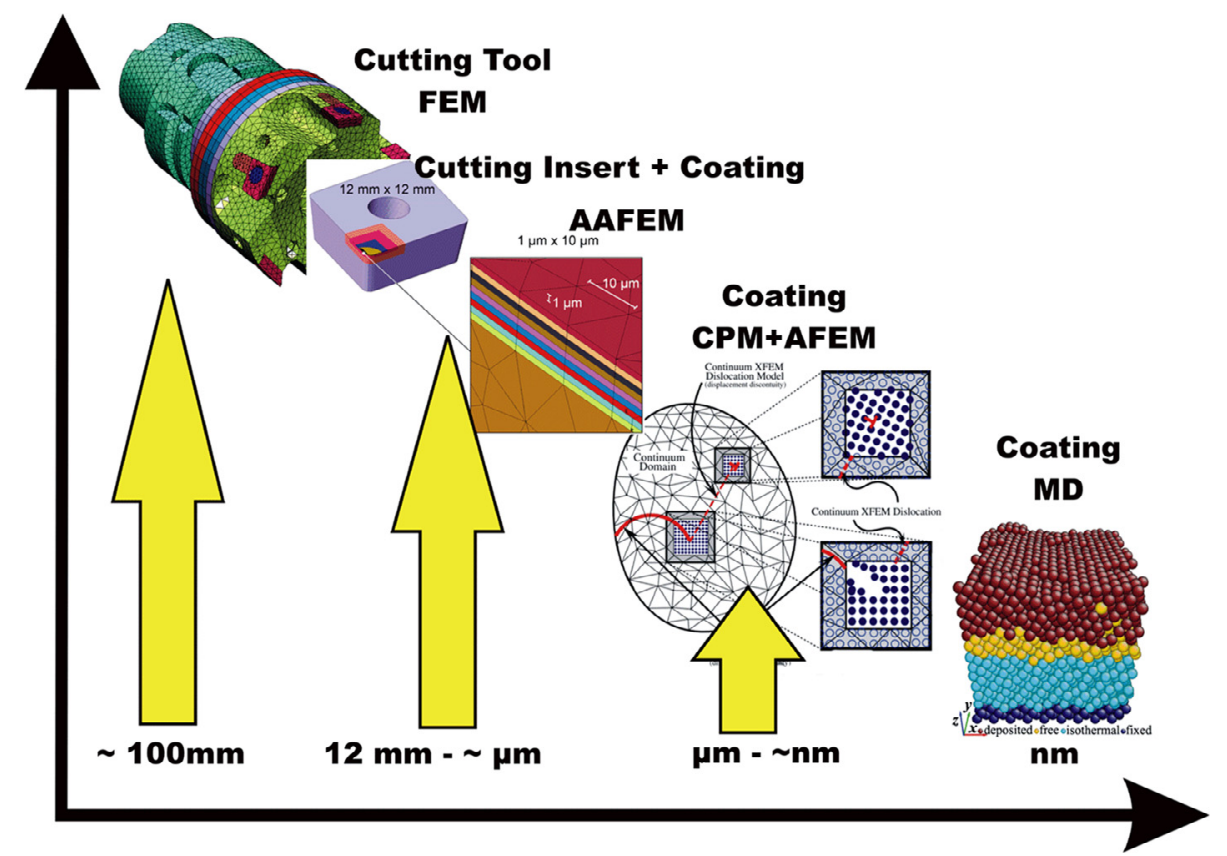

Figure 19. Top-down concept for a multiscale modelling of coating-substrate systems [94].

of personnel, materials and machine time. For a special type of cutting tool applied in high-performance cutting operations, an integrated simulation system has been developed and tested (Figure 14).
The closed-loop system enables users to relocate the prototyping process from the machine tool onto a personal computer, keeping machine tests to a minimum. This system has been tested for the multivalent applicable ratio milling tool. 
The time-to-market was strongly reduced and the same methodology can be used for other types of cutting tools [79].

\subsection{Multiscale modelling in machining}

Going back into the history, micromachining was and is an important topic within manufacturing [80-87].

The modelling task differs from other metal cutting simulation methods in the following main areas (geometry, material structure; friction; dislocations, etc., Figures 15-17).

It must be pointed out, that up to now there has been no final model or simulation code available to investigate micro cutting with the topics presented in Figure 18. Investigations into the material flow with the micro visioplasticity method have been used to verify numerical investigations - but they are very time consuming [88]. In addition, there are a lot of investigations dealing with the application of molecular dynamics - in combination with FEM simulation [89].

\subsection{Multiscale modelling in coating-substrate simulation}

Following Figure 19, the geometrical differences between the well known boundary conditions at the cutting tool clamping area, in the machine tool spindle and at the chip-tool interaction area at the coating-substrate-system are about $100 \mathrm{~mm}$ to $1 \mathrm{~nm}$.

The main four levels for investigation of Coating-SubstrateSimulation (CCS) are:

- the macroscopically level - continuum mechanics $>$ Macro FEM,

- the microscopically level - continuum mechanics $>$ Micro FEM,

- the material science based level $>$ Quasi Continuum (QC) method Crystal plasticity and Atomistic FEM,

- the atomic-scale level > Molecular Dynamics and "Firstprinciple Methods".

The commonly used method is the well known finiteelement-method for the macroscopically and microscopically coating-substrate investigation. The basic research at this time is focused to develop the methods separately on one hand and finding methods to close the gap between these methods on the other hand (Figure 19).

First steps to close the gap between the four levels of simulation have been presented [8].

The goal of the European Project $[90,91]$ was to develop an integrated multiscale modelling approach to link molecular dynamics crystal plasticity and continuum mechanics modelling activities for the applications.

A new Advanced Adaptive Finite Element code [92] has been used to investigate the continuum mechanics modelling of typical cutting tools.

Molecular Dynamics (MD) techniques have been applied to model atom deposition processes and the atomic structure and interfaces to achieve optimal coating microstructures.
The MD method was used to simulate the formation of lattice structures of coatings and layer interfaces in thermo-chemical processes and the results were used as input for nano- and micro-mechanics modelling for defining material structures.

Continuum diffusion models are being used to simulate such processes as plasma nitriding, plasma carburising and plasma nitro carburising. These surface modification processes have been widely used in the design of multilayered surface systems to improve their load supporting capacity. The outcomes have been used to define material structures as inputs for mechanics analysis.

New physically based constitutive equations based on evolving micro structural state variables (e.g. dislocation density) were developed to predict damage. These, incorporated with the newly developed controlled Poisson Voronoi tessellation technique for generating virtual grain structures, enable the load bearing capacity of polycrystalline films and multilayers to be predicted.

In parallel, mesoscopic (called atomic) and crystal plasticity FEM modelling capabilities and facilities for predicting deformation and failure of individual layers of nano-/micro-coatings have been applied. The "atomic" lattice model is solved by finite element methods. Elements are used like bars or trusses.

The behaviour of the bar is described by an interatomic potential. This enables an atomic lattice to be modelled by a truss-like assemblage of members that deform according to a prescribed interatomic potential, which governs their relative separations under applied loading. A key feature of the atomic finite element method is that it results in a finite element equation with displacement degrees of freedom, hence an atomic finite element mesh can be directly coupled to other element types and larger scales. Discrete dislocation models have also been used to model at scales between the atomic and crystal scales, with concurrent coupling. The lattice structure of coatings, atomic mismatch and dislocations at layer interfaces modelled at the atomistic level is used for the FEM models. Therefore, an integrated technique to determine mechanical properties of nano- and micro-scale coatings have been developed [93-98].

\section{Summary}

This paper presents a comprehensive summary of the stateof-the-art developments in the modelling of machining operations with special consideration of the application of models and simulation techniques in the daily-job in an industrial environment as well as an outlook to next steps in modelling. As seen, significant advances have been made in developing advanced computational tools and analytical methods for a physically based modelling at the single process level and its application in the industry. There is a lack in modelling of closed-loop design, which could be one of the main interesting topics within the next decade. Some other interesting aspects such as friction in cutting, residual stress topics, part distortion due to cutting and initial residual stresses due to previous manufacturing steps, cutting tool wear task, material law design and aspects of machining stability has been excluded in this review - but are actually existing in the literature $[20,99,100]$. 


\section{References}

1. R.W. Ivester, et al., Assessment of machining models: Progress report, Mach. Sci. Technol. 4 (2000) 511-538.

2. J. Leopold, Proceeding's of the 3rd Int. Workshop on Modelling of Machining Operations, Sydney, 2000.

3. H. Weber, T.N. Loladze, Grundlagen des Spanens, VEB Verlag Technik, Berlin, 1986.

4. I. Time, Soprotivlenie Metallov i Dereva Rezanyu, St. Petersburg, 1870.

5. M.W. Merchant, Mechanics of metal cutting process. I. Orthogonal cutting and a type 2 chip, J. Appl. Phys. 16 (1945) 267-275.

6. H. Tresca, Mémoire sur le rabotage des métaux, Paris, 1877.

7. A. Mallock, The action of cutting tools, Proc. Roy. Soc. London 33 (1881) 127-139.

8. K.A. Svorykin, Rabota i Usilie Neobkhodimyya dlya Oteleniiya Metallichcskikh Struzhek, Moscow, 1883.

9. K. Zuse, http://zuse.zib.de/collection/aseFhOEB5XjjvE2c, 1938.

10. O.C. Zienkiewicz, Y.K. Cheung, The Finite Element Method in Structural Mechanics, McGraw-Hill, London, 1967.

11. H. Weber, et al., Wiss. Schriftenreihe der TH Karl-Marx-Stadt, 1986, 11, ISSN 0323-6374.

12. J. Leopold, U. Semmler, K. Hoyer, Applicability, robustness and stability of the Finite Element analysis in metal cutting operations, Proc. CIRP Workshop on Modelling of Machining, Nantes, 1999.

13. J. Leopold, Wiss. Schriftenreihe der TH Karl-Marx-Stadt, 1, 1980, ISSN 0323-6374.

14. H. Weber, J. Leopold, Wiss. Schriftenreihe der TH Karl-MarxStadt, 1981, ISSN 0323-6374.

15. H. Weber, J. Leopold, Acta Technica Academia Scientiarum Hungaricae 86 (1978) 287-300.

16. G.R. Johnson, W.H. Cook, Proc. of the 7th International Symposium on Ballistics, Netherlands, 1983, pp. 541-547.

17. F.J. Zerilli, R.W. Armstrong, Dislocation-mechanics-based constitutive relations for material dynamics calculations, J. Appl. Phys. 61 (1987) 1816-1825.

18. E. Usui, K. Hoshi, Slip-line fields in metal machining which involve centered fans, Proc. of Int. Production Engineering Research Conference, Pittsburgh, ASME, 1963, pp. 61-71.

19. P.J. Arrazola, T. Özel, Investigations on the effects of friction modeling in finite element simulation of machining, Int. J. Mech. Sci. 52 (2010) 31-42.

20. P.J. Arrazola, et al., Recent advances in modelling of metal machining processes, CIRP Ann. - Manuf. Technol., 2013.

21. http://www.thirdwavesys.com/

22. J. Leopold, et al., 8th Int. Workshop on Computational Mechanics of Materials, Stuttgart, October, 1998, pp. 8-9.

23. J. Leopold, M. Meisel, 9th Int. Workshop Computational Mechanics and Computer Aided Design of Materials, Berlin, October, 1999, pp. 4-5.

24. J. Leopold, M. Meisel, Comput. Mater. Sci. 19 (2000) 205-212.

25. J. Leopold, et al., Surf. Coat. Technol. 142-144 (2001) 916-922.

26. J. Leopold, M. Meisel, Report on HPS-CSS (HPS-CSS has been supported by the ESPRIT HPCN programme from the European Commission), 2001 (unpublished).
27. H. Oosterling, et al., Low friction, $\mathrm{M}_{0} \mathrm{~S}_{2}$-composite coated cutting tools for dry, high speed machining of steel; LoFriCo Final technical report - BRST-CT98-5361, 2001 (unpublished).

28. J. Leopold, Mechanical and thermal behaviour of coatingsubstrate-systems investigated with parallel FEM, Proc. Int. Conf. on Metallurgical Coatings and Thin Films - ICMCTF 2002, San Diego/USA, April 22-26, 2002.

29. L.C. Cho, C. Abhijit, A boundary element method analysis of the thermal aspects of metal cutting processes, Trans. ASME, J. Eng. Ind. 113 (1991) 311-319.

30. E.P. Stephan, Coupling of boundary methods and finite element methods, E. Stein, R. de Borst, T.J.R. Hughes (Eds.), Encyclopedia of Computational Mechanics, Chapter 13: Fundamentals, Vol. 1, John Wiley \& Sons, 2004.

31. J. Kuhnert, A. Mattes, J. Leopold, Internal report, FhG IWU; FhG ITWS and TU Berlin, 2005.

32. J. Kuhnert, A. Tramecon, P. Ullrich, Proc. of the EUROPAM Conf., 2000.

33. S.S. Akarca, W.J. Altenhof, A.T. Alpas, Proceedings of the 10th International LS-DYNA Users Conference, 2008.

34. E. Uhlmann, et al., Proc. of the CIRP Conf. on Modelling of Machining Operations, Donostia-San Sebastian, pp. 145-151, (2009).

35. V. Gyliene, V. Ostasevicus, M. Ubartas, Proc. of the 9th European LS-DYNA Conf. 2013 and Proceedings of the 12th CIRP Conference on Modelling of Machining Operations, 145-151, 2009.

36. C. Espinosa, et al., Proc. of the 10th Int. LS-DYNA Users Conference, 2008.

37. N. Ikawa, et al., Ann. CIRP, 40 (1991) 551-554.

38. S. Shimada, et al., Feasibility study on ultimate accuracy in microcutting using molecular dynamics simulation, Ann. CIRP 42 (1993) 91-94.

39. R. Rentsch, I. Inasaki, Ann. CIRP 44 (1995) 295-298.

40. H. Tanaka, S. Shimada, L. Anthony, Requirements for ductilemode machining based on deformation analysis of monocrystalline silicon by molecular dynamics simulation, Ann. CIRP 56 (2007) 53-56.

41. J. Leopold, Werkzeuge für die Hochgeschwindigkeitsbearbeitung, HANSER, 1999.

42. J. Leopold, et al., Fliehkraftverhalten von Feinbohrwerkzeugen bei hohen Drehzahlen, VDI-Z III (1996) 48-50.

43. J. Leopold, et al., Festigkeits- und Verformungsanalyse von Werkzeugen für die Hochgeschwindigkeitsbearbeitung, DIMA 12 (1997) 33-39.

44. J. Leopold, G. Schmidt, A. Kieninger, FEM-Analyse modular aufgebauter HSC-Werkzeuge mit 3-D einstellbaren Schneiden, DIMA 3 (2000).

45. http://www.hsm.tu-darmstadt.de/index_hsm/conference_program hsm/conferenceprogram_hsm.de.jsp

46. http://www.rcmt.cvut.cz/hsm2014/en/

47. http://hpc2014.berkeley.edu/

48. D.A. Dornfeld, S.L. Ko, A study on burr formation mechanism, Trans. ASME. J. Eng. Mat. Technol. 113 (1991) 75-87.

49. J. Leopold, Prediction and verification of models of burr formation, Int. J. Mater. Product Technol. 35 (2009) 89-117.

50. A. Freitag, C. Sohrmann, J. Leopold, Simulation of burr formation, Proc. of the 8th CIRP Int. Workshop on Modeling and Machining Operations (2005) 641-650. 
51. A. Stoll, J. Leopold, R. Neugebauer, Hybrid methods for analysing burr formation in 2D-orthogonal cutting, Proc. of the 9th CIRP Int. Workshop on Modelling of Machining Operations, Bled, Slovenia, May 11-12, 2006.

52. J. Leopold, G. Schmidt, K. Hoyer, A. Stoll, Modelling and simulation of burr formation - State-of-the-art and future trends, Proc. of the 8th CIRP Int. Workshop on Modelling of Machining Operations, Chemnitz, Germany, May 11-12, 2005.

53. J. Regel, A. Stoll, J. Leopold, Numerical analysis of crack propagation during the burr formation process of metals, Int. J. Machining and Machinability of Materials, 54-68.

54. A. Stoll, N. Ahmed, A.V. Mitrofanov, V. Silberschmidt, J. Leopold, Influence of ultrasonically assisted cutting on burr formation, Proc. of the 9th CIRP Int. Workshop on Modelling of Machining Operations, Bled, Slovenia, May 11-12, 2006.

55. M. Dix, R. Leopold, Investigations on the influence of local material properties of burr formation, Proc. of the 10th CIRP Int. Workshop on Modeling of Machining Operations, Reggio Calabria, Italy, August 27-28, 2007.

56. J. Leopold, A. Mucha, Non-stick coating for clean manufacturing - cleanability in high-performance cutting, Proc. of the Conf. NANOFAIR, Karlsruhe, 2006.

57. J. Leopold, R. Neugebauer, M. Löffler, M. Schwenck, P. Hänle, Influence of coating-substrate-systems on chip and burr formation in precision manufacturing, Proc. IMechE Part B: J. Eng. Manuf., 219 (2005) 1-8.

58. J. Leopold, T. Matsumura, Modelling of burr formation of coated-cutting tools for clean manufacturing, Proc. of the 5th Int. Conf. on Leading Edge Manufacturing in 21st Century LEM21, Osaka, 2009.

59. T. Matsumura, J. Leopold, Simulation of drilling process for control of burr formation, Journal of Advanced Mechanical Design, Systems and Manufacturing 4 (2010) 966-975.

60. S.Y. Hong, I. Markus, W. Jeong, New cooling approach and tool life improvement in cryogenic machining of titanium alloy Ti-6Al-4V, Int. J. Mach. Tools Manuf. 41 (2001) 2245-2260.

61. R. Ghosh, Z. Zurecki, J.H. Frey, Cryogenic machining with brittle tools and effects on tool life, Proc. of IMECE'03, Paper No.: ICMECE2003-42232.

62. M. Dhananchezian, M. Pradeep Kumar, A. Rajadurai, Experimental investigation of cryogenic cooling by liquid nitrogen in the orthogonal machining process, International Journal of Recent Trends in Engineering 1 (May 2009) 55-59.

63. S.C. Jun, Lubrication effect of liquid nitrogen in cryogenic machining friction on the tool-chip interface, Journal of Mechanic, Science and Technology (KSME Int. J.) 19 (2005) 936-946.

64. F. Pušavec, A. Stoić, J. Kopač, The role of cryogenics in machining processes, Technical Gazette 16 (2009) 3-10.

65. F. Pušavec, J. Kopač, Sustainability assessment: Cryogenic machining of inconel 718, Strojniški vestnik, J. Mech. Eng. 57 (2011) 637-647.

66. T. Lu, O.W. Dillon, Jr., I.S. Jawahir, A thermal analysis framework for cryogenic machining and its contribution to product and process sustainability, Proc. of the 11th Global Conference on Sustainable Manufacturing - Innovative Solutions, Berlin, pp. 262-267, 2013.

67. http://www.mag-ias.com/en/mag/technologies.html

68. J. Leopold, W. Arnold, H. Gründemann, Ein integriertes Gleitlinien-Finite-Elemente-Modell zur Spannungsberechnung vor der Scherlinie, Wiss. Z. d. Techn. Hochschule Karl-MarxStadt, 21 (1979) 185-189.
69. G. Spur, J. Leopold, G. Schmidt, Ermittlung des Spannungs-, Verformungs- und Temperaturverhaltens spanned bearbeiteter Werkstücke mit Hilfe der Visioplastizität und der Finiten Elemente Methode, Proceedings of the DFG Priority Prpogramm "Wirkflächenreibung bei inelastischer Verformung metallischer Werkstoffe, Hannover, 1995.

70. J. Leopold, et al., Wiss. Z. d. Techn. Hochschule Karl-MarxStadt 21 (1979) 185-189.

71. J. Leopold, FEM modelling and simulation of 3D-chip formation, Proc. of the CIRP Int. Workshop on Modelling of Machining Operations, Atlanta, 1998.

72. J. Leopold, G. Schmidt, Proc. of the second CIRP international workshop on modelling of machining operations, Nantes, January 25-26, 1999.

73. J. Leopold, Proc. of the 3rd International Workshop on Modelling of Machining Operations, Sydney, 2000.

74. X.P. Li, K. Lynkaran, A.Y.C. Nee, A hybrid machining simulator based on predictive machining theory and neuronal network modelling, Journal of Material Processing Technology 89-90 (1999) 224-230.

75. M. Klärner, J. Leopold, L. Kroll, Analysis of clamping within a fixing system, Lecture Notes in Computer Science 5315 (2008) 356-367.

76. J. Leopold, et al., Investigations to new fixturing principles for aerospace structures, Proc. of the Int. Conf. on Applied Production Technology, Bremen, 2007.

77. J. Leopold, et al., Interaction between machining and new fixturing principles for aerospace structures, Proc. of ESAFORM, 2008.

78. AFFIX consortium. Affix - aligning, holding and fixing flexible and difficult to handle components, http://www.affix-ip.eu, 2006.

79. J. Leopold, et al., High performance cutting with optimized cutting tools, Proc. of the 4th CIRP Int. Conf. on High Performance Cutting, Gifu, 201.

80. M. Sato, K. Kato, K. Tuchiya, Effect of material and anisotropy upon the cutting mechanism, Trans. JIM. 9 (1978) 530-536.

81. W. König, N. Spenrath, The influence of the crystallographic structure of the substrate material on surface quality and cutting forces in micromachining, Proc. 6th Int. Precision Engng. Seminar, Braunschweig, Germany, pp. 141, 1991.

82. J.D. Kim, D.S. Kim, Theoretical analysis of micro-cutting characteristics in ultra-precision machining, J. Mater. Process. Technol. 49 (1995) 387-398.

83. W.B. Lee, C.F. Cheung, S. To, Characteristics of micro-cutting force variation in ultraprecision diamond turning, Mater. Manuf. Process. 16 (2001) 177-193.

84. W.B. Lee, C.F. Cheung, S. To, A microplasticity analysis of micro-cutting force variation in ultra-precision diamond turning, Transactions of the ASME 124, May (2002), 170-177.

85. A. Simoneau, E. Ng, M.A. Elbestawi, Grain size and orientation effects when microcutting AISI 1045 steel, CIRP Ann. 56 (2007) 57-60.

86. V. Schulze, J. Michna, F. Zanger, R. Pabst, Modelling the process-induced modifications of the microstructure of work piece surface zones in cutting processes, Advanced Materials Research 223 (2011) 371-380.

87. M. Abouridouane, F. Klocke, D. Lung, O. Adams, A new 3D multiphase FE model for micro cutting ferritic-pearlitic carbon steels, CIRP Ann. 61 (2012) 71-74. 
88. J.W. Erben, Mikrovisioplastische Untersuchungen an ein- und zweiphasigen metallischen Werkstoffen als Bindeglied zur numerischen Modellierung der Mikrostruktur, Abschlussbericht DFG Le746/17, 1999.

89. G. Schmidt, R. Leopold, R. Neugebauer, FE-simulation of nonlinear dynamical effects in coating-substrate-systems, 4th Int. Symposium: Investigations of Non-Linear Dynamic Effects in Production Systems, Chemnitz, Germany, April 8-9, 2003.

90. FP7 project, "Multiscale Modelling for Multilayered Surface Systems" (M3-2S), Grant No: NMP3- SL-2008- 213600.

91. http://ec.europa.eu/research/industrial_technologies/pdf/modellingbrochure_en.pdf

92. J. Leopold, et al., An advanced adaptive finite element code for coating-substrate simulation, J. Multiscale Modelling 03 (2011) 91.

93. A.V. Byakova, J. Leopold, Effect of stress state on failure resistance of brittle high-strength coatings, Unpublished report, 1996.

94. J. Leopold, R. Wohlgemuth, D. Shan, Y. Qin, Modelling and simulation of coating-substrate-systems: state-of-the-art and future trends, Proc. of the Conference "THEA Coatings", Thessaloniki, 2011.

95. J. Leopold, R. Wohlgemuth, J. Lin, S.V. Subramanian, T. Matsumura, New concepts for micro-structural simulations of coating-substrate-systems, Proc. of the 12th CIRP Conf. on Modelling of Machining Operations, Donostia, San Sebastián, Spain, 1 (2009) 117-124.

96. S. Wang, J. Lin, D. Balint, Modelling of failure features for TiN Coatings with different substrate materials, J. Multiscale Modelling 03 (2011) 49.

97. D.Q. Qin, et al., Prediction of residual stress in multilayered coatings with a linear elastic model incorporating density functional theory calculations, J. Multiscale Modelling 03 (2011) 65.

98. R. Neugebauer, R. Wertheim, U. Semmler, The atomic finite element method as a bridge between molecular dynamics and continuum mechanics, J. Multiscale Modelling 03 (2011) 39.

99. J. Leopold, H. Gründemann, W. Totzauer, Kontinuumsmechanische Methoden zur Modellierung des Spanbildungsprozesses, Sitzungsberichte der AdW der DDR, 12N/1979, 51-81.

100. C.A. Luttervelt, et al., Present situation and future trends in modelling of machining operations, CIRP Ann. 47 (1998) 587-626.

101. E.H. Lee, B.W. Shaffer, The theory of plasticity applied to a problem of machining, Transaction of ASME 73 (1951) 405-413.

102. M.C. Shaw, Metal cutting principles. 3rd ed., MIT Press, Cambridge, 1954.

103. W.B. Palmer, P.L.B. Oxley, Mechanics of orthogonal machining, Proceedings of the Institute of Mechanical Engineers 173 (1959) 623-654.

104. H. Weber, Mechanik der Spanbildung, Wiss. Z. der TH Karl-Marx-Stadt 11 (1969) 597-629.

105. M.G. Stevenson, P.L.B. Oxley, An experimental investigations of the influence of strain rate and temperatures on the flow stress properties of a low carbon steel using machining test, Proc. Inst. Mech. Eng. 185 (1970) 741-754.

106. R. Makino, E. Usui, An analysis of stress and strain distributions in the plastic region of slow speed, steady-state machining, Bull. Japan Soc. of Prec. Engg. 7 (1973) 43-50.

107. N. Fang, I.S. Jawahir, An analytical predictive model and experimental validation for machining with grooved tools incorporating effects of strains, strain-rates and temperature, CIRP Annals - Manufacturing Technology 51 (2002) 83-87.

Cite this article as: Leopold $\mathrm{J}$ : Approaches for modelling and simulation of metal machining - a critical review. Manufacturing Rev. 2014, 1, 7 . 